\title{
The Will to Die and the Will to Live: An Ontological Quest for Teenagers Who Suffer from Depression, a Study from Malaysia
}

\author{
Jin Kuan Kok
}

\begin{abstract}
The prevalence of youth depression in Malaysia has increased over the years. This study aims to investigate the experience of teenage depression. In-depth interviews were conducted with university students who were diagnosed with depression in their teens but were in a recovery stage. An in-depth thematic approach was used for data analysis. The paper presents two case studies and reveals some depression narratives in which the participants asked ontological questions about the meaning of their existence. The themes that emerged from the teenagers' depression narratives are in concordance with Martin Heidegger's ontological perspective of "What it means to be in the world". Findings reveal the themes of "Being thrown into the world", "care" and temporality, thus provide insights for parents and educators to better understand the society and culture in which the teens are embedded.
\end{abstract}

Index Terms-Teenage depression, youth depression, meaning of life, ontological questions.

\section{INTRODUCTION}

According to the medical model, depression is known as affective disorder or mood disorder. This diagnosis includes problematic biological descriptions such as significant weight gain or weight loss; insomnia or hypersomnia; mood disorders such as loss of interest; even preoccupation with destructive emotions that results in a change of activity level (retardation or agitation), regressive and self-punitive wishes [1]. Other symptoms include, among others, lack of energy, inability to concentrate and sleep disturbance [2]. Looking at the definition from a medical model has led to depressed people being judged as problematic, exhibiting deviant behaviours. People who suffer from depression are treated as though they have problems on their own. The cultural or environmental is not seen as having anything to do with the contribution or maintenance of this "illness". The context of their experience seems to be eclipsed. However, human beings are inseparable from the world in which they live; they are part of the world and also the products of the world. What does their context mean for people who suffer depression? How do they perceive their world and what meaning do they make out of the world? What are their struggles? Many adult depression cases can be traced back to depressive episodes in childhood and adolescence [3]. Depression in teenagers left

Manuscript received July 12, 2013; revised September 22, 2013. This work was supported UTAR Research Fund.

J. K. Kok was with the Universiti Tunku Abdul Rahman (UTAR), Jalan Universiti Bandar Barat, 31900 Kampar, Perak, Malaysia. She is now with the Department of Psychology and Counselling, Faculty of Arts and Social Science (e-mail: kokjk@utar. edu.my). unrecognised or untreated will interfere later stages of development and lead to negative lifelong consequences for psychological health and wellbeing. Studies of teenage depression provide important insights for us to understand depressives and their experience of their world that gave rise to their illness. Therefore this research focused on in-depth exploration of the teenage experience of depression.

Recently there has been an emphasis on the impact of environment, culture and society on individuals. The importance of narratives in the conceptualization and understanding of depression was also highlighted [4]. Depression is no longer being viewed solely from a medical perspective, or an adaptation issue but it is also seen as a social issue in cases of bullying or victimization [5]. The external, observable, description of the depressive symptoms such as emotional disturbance, sadness, tearfulness, or the objective investigation of measuring self-esteem is not adequate to grasp a full understanding of what it is like to be struggling with this increasing common illness. Researchers started to use a narrative approach so as to reveal the internal landscape, the struggles and experience of teenage depression. Using a narrative approach can lead to a better understanding of how young people experience depression and how they make sense of their way of life. The questions they normally ask themselves during this critical period and how they interpret the larger context of their lives will provide insights to help us to better understand them.

\section{TheORETICAL PERSPECTIVE AND METHOD}

\section{A. Theoretical Perspective}

This paper adopts the perspective initialled by Martin Heidegger. Heidegger held that the searching for the meaning of life is an ontological enquiry. It questions what it means to be living as a person. Heidegger put it "What it meant by Being" (In German, dassein). To be more exact, from the Heidegger's perspective, the question would be "What it does it mean to-be-in-the-world?" [6]. Heidegger objects to objective enquiry into the meaning of life, as if a person can stand outside of his/her own life to investigate its meaning. The context or the environment of a person is not 'out there' [7], before we are aware of what we are experiencing we already part of it.

This condition of being in the world provides us a glimpse of understanding that feeling moody is not some phenomenon that exclusively within us, nor outside of us, but this is a consequence of the interaction between us and the world outside, while we are currently existing in the world. 
This is what Heidegger means "Being in the world" [6], [7].

Therefore depression is not something that "happens to us" as if we are passive victims. And it is not something wrong with us that we actively acquire. Depression is a product of "being in the world". Therefore treating depressed people without paying attention to "the world" is insufficient. Blaming "the world" without examining the experience of the person is also biased. Using objective tests common in much psychological investigation is seen as detached and may be irrelevant to what the depressed person is experiencingubmit your manuscript electronically for review.

\section{B. Method}

In-depth interviews were conducted with 10 teenagers who were diagnosed with depression or who have recovered from depression. Three sessions of unstructured interviews sessions were carried out with each participant. All of them were volunteer participants. They were briefed about the purpose of this study and each interview lasted for about one hour to one and a half hours. The recruitment of the research participants was by advertisement on Facebook and snowball samplings. Some participants introduced their friends, who had gone through similar experiences, to us. All interviews were transcribed and an in-depth thematic approach was used to analysis the emerging themes from the narratives. The verbatim from the participants will be presented to illustrate the emerging themes. In-depth qualitative descriptions of participants' lived experiences will be provided as follows.

\section{CASE PRESENTATION}

\section{A. Case A}

Ms A, a 22 year-old university student, was diagnosed with depression 3 years ago when she found she couldn't cope with the new university environment. She was accepted on a forensic science course in a prestigious university in Kelatan which is very far away from her home town. She had to leave home and stay in a new and strange environment which was totally different from her previous environment. She realized that her classmates were very competitive. The depression began with a panic attack during the exam. Her depressive symptoms were sadness, feeling lost, moodyness, lost of interests and often crying for no apparent reason. It got worse when she was rejected by her boy friend. She took one semester off and was planning to go back to the university. But whenever she thought of going back to the university the anxieties came back so she rested for another semester. Later she went to another private university near her home town. The relapse happened when she was rejected by her second boy friend. She had three attempts at suicide, twice taking pills and once trying to find a building to jump from. She was still under medication but is on the way to recovery.

\section{B. Case B}

Ms B was 24, diagnosed with depression at the age of 15 . She was the middle child of a single mother who works as a medical doctor. She felt that her sister had a better life, studying in a nearby college. She mentioned her mother treated her sister and brother well whereas she was treated as a maid at home. Her mother would go visit her sister three times in a week but she was made to cook and do the house chores of the family. When she became frustrated and stopped doing the house work when she was 15 , her mother poured hot water on her, hit her with a bloom and even broke her hand. She was made to tell lies at the hospital. Hence she hated her mother. She hated the school environment and even the school counsellor was her mother's good friend who would report her behaviour to her mother. Her depressive symptoms were tiredness, agitation and irritation with her mum, disturburbed sleep, and hypersomnia. She made two suicide attempts. The first time she tried to take panadol tablets after scoring straight as in her PMR examination, the second time was after she realize that she did not do well in her SPM Preliminary Examination as she anticipated being stuck at home with her mother as she was not able to get a scholarship

\section{FINDINGS}

Emerging themes: (A) Being thrown into the world; (B) Care; (C) What does future mean; (D) The will to die and the will to live

\section{A. The Theme of "Being Thrown into the Worlde"}

Both participants felt out of place in their environment. They felt they were living out of place. Ms A found herself couldn't cope with the new academic challenges. She felt inadequate and rejected and felt lonely even when she was with others. Ms B felt rejected and abused by her own mother. They both dreaded their school and home environments.

Ms A: "In the university I don't know what I'm doing...it was like my peers are learning things and they write the report but I don't know what I'm doing. I just copy the report from my friend. That feeling of not knowing what I was doing was really scary. I was like drowning, being thrown into the sea and I couldn't swim".

Ms A experienced turbulence and dread as she did not know what she was trying to study. She wanted to know what was happening but she could not. Besides, she also experienced two rejections in her emotional relationships.

Ms A: "The first time in the public university, that boy suddenly told me he had no feeling towards me. It was like he had stolen my heart then he said he had no more feeling. I questioned myself "am I something wrong?" The second time before another university tried to cut off the relationship, he was nice and will hold my hand and put his arm on my shoulders. But then he told me he was trying to see if we could be together".

Ms B: "I also wanted to get back to my mother who would constantly say something like "I wish that I didn't give birth to you", or 'I wish that I could kill you,' or 'if you were dead, it would be easier for me,' or so on. I felt like writing a note telling her that, 'You always wish that I were dead, and I will grant your wish'. I wanted to write the note and then killed myself so that my mom will feel sorry".

The case of Ms B shows similarities to that of Ms A. She couldn't control having being born as a middle child and being raised by a capable single mother who had a respectable career but was biased against her. She could not 
help but compare her life and her siblings' lives. She could not control the fact that her sister was having a better experience staying away from the family or that her brother was the precious son in the family. Both her suicide attempts were related to the results of examinations. When she scored too well, all of a sudden she felt empty, she thought "what is the point of scoring all As". When she didn't score well, she thought "I will be stuck with my mom forever".

\section{B. The Theme of "Care"}

During the depressed period, Ms A cared. She cared about what people thought of her, how to relate to the people around her, that the family name would be tarnished and her parents would be ashamed if she didn't succeed. She cared about being useful and cared so much about finding meaning in her life that she would rather gave up her life if she couldn't find one.

Ms A: "When I went there I found that I don't like this course, but then people here are like talking good about me. Family is putting a lot of hope on me. As my sister didn't go to university so my mother kept saying to me that I must go to the public university. If I fail to continue my study what would people say about me. If I withdraw from university then my family will have "no Face" (no pride) If people know that I have depression, I think depression is for old people, and it is not very good to have depression, people would think I am crazy, so I hide it from people....but when I was resting at home, I feel even more useless. I worked part-time in a clinic for a while, the rest of my time I watched movie, those Cantonese Drama. Then I felt like why am I sitting here for so long, and watching drama and doing nothing. I felt really useless. I want to be useful; I was like wasting my time, wasting my life".

For Ms B, she wanted revenge on her own mother. Throughout the interview, she wept many times. Although she hated her mother, she also yearned for her mother's care and attention. Deep inside her actually cared if her mother cared for her.

Ms B, "I was unwell and often fainted in school, but my mum didn't care. She took my sister to the hospital because she looked pale so she also took me, but in one go. My sister is more important than me and my brother is her precious son".

\section{The Theme of What Does “Future" Mean}

Both of the participants have asked ontological questions of the meaning of being in this world with their depressed status. They found that life is meaningless by sitting there doing nothing. They anticipate their situation will not get better and the "future" holds no hope for them. Even there is a future; it is not the future they look forward to.

Ms B: "When I was about at 15 years old, and this attempt happened right after I just got my PMR results-straight as. Even though I got straight As, I felt my life was meaningless. Even though I was getting straight as, what was the use that my life was not happy? The rest of my life would be continuing on like this, I would prefer to die. I just want to die".

Ms B: "The second time I was very hopeless because I didn't do well in my SPM Preliminary Examination. I got Bs and $\mathrm{C}$ for Biology, and therefore I thought of even though I lived on also hopeless. I would live with my mother forever and wouldn't be able to get scholarship".

\section{The Will to Die and the Will to Live}

It was found that when there is a will to die there is a will to live.

Ms A: "After I have recovered, I try to trace back what happened. Actually, I know why I didn't want to give away my life. Because I have tried three times and it didn't work. The first time I took 20 pills, the second times I took 10 pills, then the third time was I tried to find a high building to jump. Actually after I took the 20 pills, I feel very regret, immediately after I took, I already feel regret. I realize that actually I didn't want to die. I still want to study, I will think of I want to continue my life; I wanted to know what my future holds, what will be installed for me in the future? But when I was rejected by my second boy friend I did it again. So my doctor told me that I need to take care of myself as I have relapsed two times, my possibility of relapse is high. But inside me I know I didn't want to die, I have tried three times, and all the three times experience has taught me something, there is something inside me that I still want to live.

Ms B: "I didn't know what was happening at that time, I went to kitchen and took the knife. I hold the knife on one side and one hand on another side, and then I told myself that I just needed to close my eyes and brought it together and cut. But thanks God that nothing was happened because when I was just about to do that, I realized I was a coward that I didn't have the courage to do that even though I wanted to do it. When I tried to do that, suddenly I didn't know what was happened. The only feeling was I felt very scared and just dropped the knife even though I had not cut anything yet.

\section{DISCUSSION}

Heidergger held "Being in the world" is a forever in a process that we are subjectively being confronted by the happening from the environment. Our experience with the world involves an overall experience with other people, environment and even the relationship with self. This existential experience frequently makes us feel being thrown in the world. Gelven [7] comments that we feel naked when being confronted by dread "It is in tranquility and everydayness that one can avoid the confrontation of the self, but in dread one cannot avoid one's self, though one can turn away from it. That's what dread is. It is the uncanny awareness of the self as free to be either authentic or inauthentic" (uncanny means not-at-home in German) we no longer feel at-home in the world. Other psychologist or researcher may use alienation [8], [9]. Heidegger also holds that the "Being" can be expressed with a term named "care" [6], [7]. This "care" includes the care about self and others; most importantly the Being is capable of anticipating and expecting a future. Future is not a place for us to travel to but something for us to anticipate. In the cases of depressed teenagers, they care so much being in the world that they would very much to feel at home or being part of it. When they do not feel at home and the future seemed hopeless, 
either remain unchanged that they feel being trapped in it or unable to change for the better, they questioned about the existential and asked ontological questions about the meaning of life. Therefore working with teenagers who suffer from depression, we need to understand their world and the ways they view their world.

\section{CONCLUSION}

The life experience and the themes uncovered in this study have revealed an ontological quest among teenagers who suffered from depression. The participants questioned the meaning of their existence in the world. Their narratives revealed that they care about the meanings of life and their relationships with the people around them. They would rather die if their ontological quest was not satisfied. The hopeful message is that while there is a will to die, there is a will to live. This study provides some implications for counselling which would help the depressed client to make meanings from their experience as meanings are not made from an empty vacuum but in the life lived. Also, it is important to help depressed teens to have a future to look forward to.

\section{ACKNOWLEDGMENT}

The author appreciates the sponsorship from UTARRF that supported this research project. Appreciations also go to Ms Connie Wong and Mr Lai Wai Yoong who have helped in the data collection process of this study.

\section{REFERENCES}

[1] A. T. Beck, Cognitive Therapy and Emotional Disorders, New York: International University Press, 1976.

[2] S. Hyman, Manual of Psychiatric Emergencies, Boston: Little, 1988.
[3] M. Wals and F. Verhulst, "Child and adolescent antecedents of adult mood disorder," Current Opinion in Psychiatry, vol. 18, no. 1, pp. 5-19, 2005.

[4] A. Paskaleva. (2011). A Phenomenological Assessment of Depression $\begin{array}{lll}\text { Narratives. } & \text { [Online]. Available: }\end{array}$ http://ikw.uni-osnabrueck.de/en/system/files/03-2011.pdf.

[5] U. Ikechukwu, Y. SitiNor, and J. Rumaya, "Bullying and its relationship with depression among teenagers," Journal of Psychology, vol. 1, no. 1, pp. 15-22, 2010.

[6] J. Stambaugh, Martin Heidegger Being and Time, Translated and with Introduction by Joan, Chicago: The University of Chicago Press, 1972.

[7] M. Gelven, A Commentary on Heidegger's Being and Time, (Revised edition), DeKalb, Illinois: Northern Illinois University Press, 1989, ch. 2-3, pp. 21-74.

[8] D. G. Dutton and C. Karakanta, "Depression as a risk marker for aggression: A critical review," Aggression and Violent Behavior, vol. 18, pp. 310-319, 2013.

[9] R. L. Calabrese and E. J. Raymond, "Alienation: Its impact on adolescents from stable environments," Journal of Psychology, vol. 123, no. 4, pp. 397-404, July 1989.

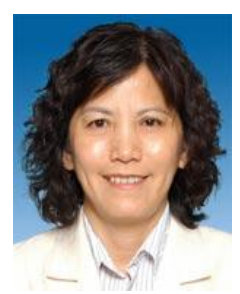

Kok Jin Kuan was born in Malaysia. BA in Chinese Literature from National Taiwan University; Master in Education (Guidance and Counselling), Durham University, England, UK; Doctorate degree in Education; Durham University, England, UK. She has extensive counselling experience working with different backgrounds of clients such as secondary school pupils with psychological and mental health challenges, parents with difficult children, family and couple counselling. She has work as a School Counsellor at Raffles Girls' Secondary School (RGSS), Singapore; Senior Counsellor at Fei Yue Family Service Centre, Singapore; Senior Lecturer at TCA College, Singapore. Her present professional occupation: Assistant Professor, Department of Psychology and Counselling, Faculty of Arts and Social Science, Universiti Tunku Abdul Rahman.

Dr Kok is a registered counsellor of Singapore Association for Counsellor (SAC) and also SAC certified supervisor for counsellor. She is specialized in using a qualitative research methodology approach under constructivist and interpretative mode, to research into areas of social science. 